\title{
СОСТАВ И КИСЛОТНАЯ ПЕРЕРАБОТКА ФОСФОРИТА УЧАСТКА РЯГАВЕРЕ
}

В результате геологоразведочных работ последних лет в Раквереском районе Эстонской ССР, южнее известного ранее месторождения Тоолсе, обнаружены крупные запасы ракушечниковых фосфоритов. Характеристика нового месторождения и перспективы его промышленного освоения приведены в $\left[{ }^{1,2}\right]$, рекомендуемая схема обогащения руды в [ $\left.{ }^{3}\right]$. Фосфоритная руда Раквереской фосфоритоносной площади отличается разнообразием форм примесных минералов [3]. Содержание соединений железа и магния (главных примесей, мешающих химической переработке фосфорита) в руде возрастает с севера на юг [']. В качестве сырья для исследования мы использовали три образца фосфоритного концентрата с участка Рягавере, полученных из фосфоритной руды методом флотации в Государственном научно-исследовательском институте горно-химического сырья (ГИГХС). Характеристика проб руды и концентрата приведена в табл. 1. При анализе фосфатного сырья и продуктов его переработки использовали методы, описанные в [4-6]. Из табл. 1 следует, что при обогащении происходило некоторое снижение отношения содержания примесей к количеству $\mathrm{P}_{2} \mathrm{O}_{5}$. Bce же отношение $\mathrm{MgO}: \mathrm{P}_{2} \mathrm{O}_{5}$ (магнезиальный модуль) осталось высоким - более $10 \%$. Пробы 1 и 2 имеют приблизительно одинаковое количество $\mathrm{P}_{2} \mathrm{O}_{5}$, но различаются по содержанию примесей. Например, проба 1 с северной части участка Рягавере весьма богата пиритом (который составляет $60 \%$ общего $\mathrm{Fe}_{2} \mathrm{O}_{3}$ ) и органическим веществом, окисляемость [7] концентрата превышает 40 единиц. В пробе 2 из средней части участка магния больше, чем в пробе 1 , пирит и органическое вещество присутствуют в незначительном количестве, зато непиритного железа больше. В соответствии с этим окисляемость пробы 2 низка.

Проба руды 3, отобранная в районе тектонического нарушения, в наибольшей степени загрязнена примесью доломита. В концентрате магнезиальный ммодуль составляет $16 \%$. Количество пирита и окисляемость низки, а содержание непиритного железа сравнимо с содержанием его в пробе 2. По остальным компонентам исследованные пробы различаются мало. $\mathrm{Fe}_{2} \mathrm{O}_{3}$ составляет около $80 \%$ суммы полуторных оксидов.

Сравнение состава проб фосфоритных концентратов разных месторождений ЭССР $\left[{ }^{8,9}\right]$ показывает, что фосфориты участка Рягавере отличаются от тоолсеского и маардуского фосфоритных концентратов более высоким содержанием магния, а пробы 2 и 3 -также более низким содержанием пирита. Исследованные пробы фосфоритного концентрата участка Рягавере по составу более близки к фосфоритным концентратам месторождения Азери, изученным нами ранее [10].

В настоящей работе исследован вариант сернокислотной переработки фосфорита Рягавере с получением экстракционной фосфорной кислоты, двойного суперфосфата, аммофоса и нитроаммофоски. Методика экопериментов описана в $\left[{ }^{11-14}\right]$. При получении этих продуктов 

(р - руда, к - концентрат)

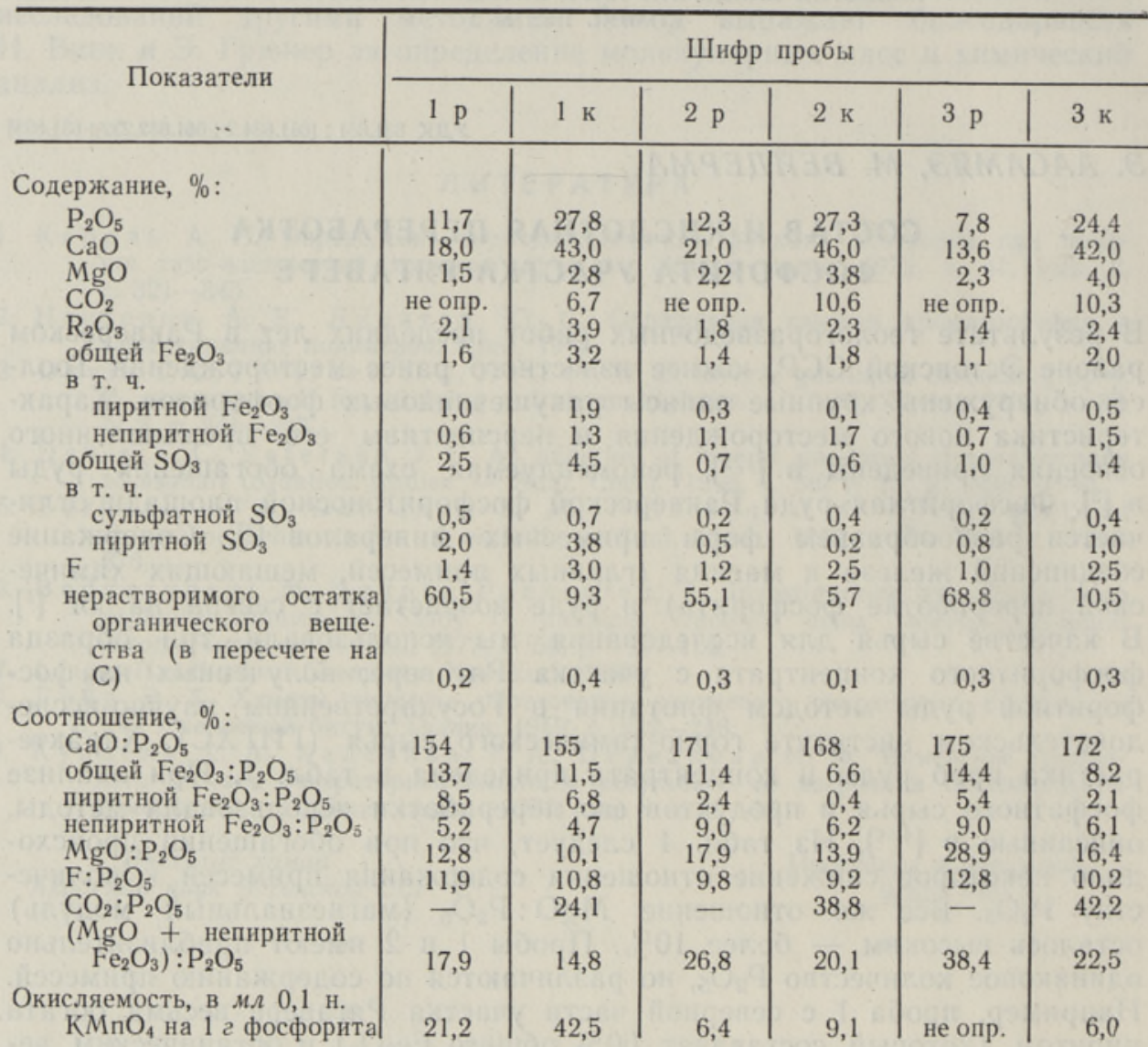

Примечан ие: Концентраты 1 к и 2 к получены анионной, 3 к - катионной флотацией.

разложение фосфорита протекает в серно- и фосфорнокислотной ореде. При этом содержащийся в фосфоритном концентрате пирит не растворяется и изменение показателей процесса вызывается главным образом различным содержанием соединений магния и растворимых форм железа (т. н. непиритного). Поэтому качество фосфоритов данного типа применительно к сернокислотной переработке целесообразно оценить по отношению $\frac{\mathrm{MgO}+\text { непиритная } \mathrm{Fe}_{2} \mathrm{O}_{3}}{\mathrm{P}_{2} \mathrm{O}_{5}} \cdot 100 \%$ (железисто-магнезиальный модуль). У фосфоритных концентратов месторождения Тоолсе этот показатель составляет 5-15, месторождения Азери $11-17$, участка Рягавере $15-22 \%$. Можно предположить, что по химикоминералогическому составу фосфоритные концентраты Рягавере наиболее сложный объект сернокислотной переработки изученных фосфоритов ЭССР. Однако путем усовершенствования технологии обогащения фосфоритной руды содержание вредных примесей в концентрате может быть снижено.

Получение двойного суперфосфата (ДС). Использовались фосфоритные концентраты тонкого помола, содержащие $18-24 \%$ фракции +71 мкм. Разложение фосфатного сырья проводилось экстракционной фосфорной кислотой, полученной из кольского апатитового кон- 
Получение двойного суперфосфата (ДС)

\begin{tabular}{|c|c|c|c|c|c|c|c|c|}
\hline \multirow{3}{*}{ Показатели } & \multicolumn{8}{|c|}{ Способ получения и номер пробы фосфорита } \\
\hline & \multicolumn{3}{|c|}{ камерно-поточный } & \multicolumn{2}{|c|}{ камерный } & \multicolumn{3}{|c|}{$\begin{array}{c}\text { бескамерно- } \\
\text { поточный }\end{array}$} \\
\hline & 1 & 2 & 3 & 1 & 2 & 1 & 2 & 3 \\
\hline \multirow{10}{*}{$\begin{array}{l}\text { Соотношенне масс } \\
\mathrm{P}_{2} \mathrm{O}_{5} \text { кислоты и фосфорита } \\
\text { Расход пеногасителя на } 100 \text { a } \\
\text { фосфорита, } 2 \\
\text { Содержание в продукте, \%: } \\
\text { усвояемой } \mathrm{P}_{2} \mathrm{O}_{5} \\
\text { водорастворимой } \mathrm{P}_{2} \mathrm{O}_{5} \\
\text { свободной } \mathrm{P}_{2} \mathrm{O}_{5} \\
\text { влаги } \\
\text { азота } \\
\text { Коэффициент разложения фос- } \\
\text { форита, \% } \\
\text { Расходные коэффищиенты на } \\
1000 \text { г усвояемой } \mathrm{P}_{2} \mathrm{O}_{5}: \\
\mathrm{P}_{2} \mathrm{O}_{5} \text { фосфорной кислоты, г } \\
\mathrm{H}^{+} \text {-нона, 2 }\end{array}$} & & & & & & & & \\
\hline & 2,7 & 3,0 & 3,7 & 2,7 & 3,0 & 2,4 & 2,7 & 3,3 \\
\hline & 0,8 & 1,6 & 4 & 0,6 & 2,5 & 2,3 & 2,7 & 12,4 \\
\hline & & & & & & & & \\
\hline & $\begin{array}{l}42,7 \\
38,8\end{array}$ & $\begin{array}{l}45,0 \\
38,6\end{array}$ & $\begin{array}{l}41,5 \\
37,4\end{array}$ & $\begin{array}{l}43,8 \\
40,6\end{array}$ & $\begin{array}{l}45,6 \\
42,6\end{array}$ & $\begin{array}{l}39,4 \\
37,6\end{array}$ & $\begin{array}{l}39,3 \\
36,7\end{array}$ & $\begin{array}{l}41,1 \\
40,2\end{array}$ \\
\hline & 0,8 & 0,1 & 0,5 & 2,7 & 2,6 & 4,4 & 4,4 & 5,6 \\
\hline & 3,9 & 3,8 & 5,6 & 0,8 & 0,9 & 3,1 & 4,1 & \\
\hline & 1,9 & 2,6 & 1,9 & & & & & - \\
\hline & 67 & 64 & 59 & 68 & 68 & 54 & 42 & 48 \\
\hline & $\begin{array}{r}800 \\
47\end{array}$ & $\begin{array}{r}827 \\
63\end{array}$ & $\begin{array}{r}862 \\
74\end{array}$ & $\begin{array}{r}798 \\
42\end{array}$ & $\begin{array}{r}818 \\
53\end{array}$ & $\begin{array}{r}818 \\
52\end{array}$ & 869 & $\begin{array}{r}870 \\
92\end{array}$ \\
\hline
\end{tabular}

Il римеч ан ие: 1 - концентрация ЭФК из апатита: а) при камерных способах $48-49 \%$; б) при поточном способе $30 \%, 2$ - продолжительность вызревания при камерном способе 10-12 сут.

центрата. Хотя по нашим предыдущим работам, для обеспечения хороших показателей процесса железисто-матнезиальный модуль в эстонских фосфоритах не должен превышать $12 \%$, настоящими опытами показано (табл. 2), что концентрат 1 можно применять при получении двойного суперфосфата, предпочтительно камерно-поточным способом. Опытный образец ДС содержал 42,7 усвояемой и $38,8 \%$ водорастворимой $\mathrm{P}_{2} \mathrm{O}_{5}$, но степень разложения фосфорита осталась низкой - $67 \%$. Расходный коэффициент $\mathrm{P}_{2} \mathrm{O}_{5}$ кислоты (без потерь) составил 800 г на 1000 г усвояемой $\mathrm{P}_{2} \mathrm{O}_{5}$. На стадии разложения фосфорита требовалось добавление пеногасителя - 1\%-ного раствора сукцинола. При других способах получения ДС и с применением других проб фосфорита Рягавере показатели процесса значительно хуже (табл. 2).

Получение экстракционной фосфорной кислоты (ЭФК). Опыты проводили в дигидратном режиме с применением серной кислоты в количестве от 90 (при переработке проб фосфорита $1 \mathrm{~K}$ и 2 к, табл. 1) до $105 \%$ (разложение фосфорита 3к) от стехиометрической нормы на осаждение ионов кальция.

Результаты экспериментов показывают, что из изученных проб фосфорита можно получить продукционную кислоту с концентрацией $\mathrm{P}_{2} \mathrm{O}_{5}$ $20-24 \%$ при коэффициенте выхода 94-97\%. Наиболее пригодным сырьем, как и в опытах получения ДС, оказался фосфорит 1. При его переработке расходный коэффициент $\mathrm{H}_{2} \mathrm{SO}_{4}$ составил $2740-2840$ г на 1000 г извлеченной $\mathrm{P}_{2} \mathrm{O}_{5}$, а скорость фильтрации при промывке фосфогипса $1,2-1,5 \mathrm{~m}^{3} / \mathrm{m}^{2} \cdot \varkappa$. Магний извлекали из фосфорита в жидкую фазу приблизительно на 80 , непиритное железо на $90 \%$. При концентрации $\mathrm{P}_{2} \mathrm{O}_{5} 20 \%$ продукционная кислота имела общую степень нейтрализации, равную $30 \%$ (табл. 3). В сравнении с переработкой тоолсеского фосфорита [ ${ }^{9}$ ] расход $\mathrm{H}_{2} \mathrm{SO}_{4}$ был на $10-15 \%$ выше, кислота более загрязнена примесью магния. В экспериментах с пробами 2 и 3 
Показатели процесса получения ЭФК с концентрацией $\overrightarrow{\mathrm{P}}_{2} \mathrm{O}_{5} 20 \%$

\begin{tabular}{|c|c|c|c|}
\hline \multirow{2}{*}{ Показатели } & \multicolumn{3}{|c|}{ Пробы фосфорита } \\
\hline & 1 & 2 & 3 \\
\hline $\begin{array}{l}\mathrm{P} \text { aсход } \mathrm{H}_{2} \mathrm{SO}_{4} \text { на } 1000 \text { г извлеченной } \mathrm{P}_{2} \mathrm{O}_{5} \text {, ट } \\
\text { Скорость фильтрации при промывке фосфо- } \\
\text { гипса, } M^{3} / M^{2} \cdot \varphi\end{array}$ & $\begin{array}{r}2740 \\
1,5\end{array}$ & $\begin{array}{r}3040 \\
0,9\end{array}$ & $\begin{array}{r}3200 \\
1,3\end{array}$ \\
\hline $\begin{array}{l}\text { Коэффициент извлечения, \%: } \\
\mathrm{P}_{2} \mathrm{O}_{5} \\
\mathrm{MgO} \\
\mathrm{Fe}_{2} \mathrm{O}_{3} \text { (непиритной) } \\
\mathrm{F}\end{array}$ & $\begin{array}{l}99 \\
81 \\
90 \\
47\end{array}$ & $\begin{array}{l}98 \\
85 \\
93 \\
40\end{array}$ & $\begin{array}{r}97 \\
100 \\
93 \\
51\end{array}$ \\
\hline $\begin{array}{l}\text { Соотношение в продукционной кислоте, } \% \text { : } \\
\mathrm{SO}_{3}: \mathrm{P}_{2} \mathrm{O}_{5} \\
\mathrm{MgO}_{\mathrm{P}_{2} \mathrm{O}_{5}} \\
\mathrm{Fe} \mathrm{O}_{3}: \mathrm{P}_{2} \mathrm{O}_{5} \\
\mathrm{~F}: \mathrm{P}_{2} \mathrm{O}_{5}\end{array}$ & $\begin{array}{l}5,5 \\
8,7 \\
4,9 \\
5,2\end{array}$ & $\begin{array}{r}12,3 \\
12,4 \\
6,2 \\
4,0\end{array}$ & $\begin{array}{r}21,8 \\
17,0 \\
5,8 \\
4,5\end{array}$ \\
\hline $\begin{array}{l}\text { Степень нейтрализации продукционной кис- } \\
\text { лоты, \% }\end{array}$ & 30,5 & 36,5 & 41,0 \\
\hline
\end{tabular}

Получение аммофоса (АФ) и нитроаммофоски (НАФК)

\begin{tabular}{c|c|c|c}
\hline \multirow{2}{*}{ Показатели } & \multicolumn{3}{|c}{ Пробы фосфорита } \\
\cline { 2 - 3 } & 1 & 2 & 3 \\
\hline
\end{tabular}

I получение аммофоса

Содержание в продукте, \%:

усвояемой $\mathrm{P}_{2} \mathrm{O}_{5}$

водорастворимой $\mathrm{P}_{2} \mathrm{O}_{5}$

азота

$\mathrm{H}_{2} \mathrm{O}$

Сорт аммофоса

\begin{tabular}{|c|c|c|} 
& & \\
50,9 & 45,4 & 39,9 \\
45,1 & 37,5 & 35,4 \\
11,9 & 11,6 & 10,1 \\
0,6 & 1,1 & 0,5 \\
B/c & B/c & -
\end{tabular}

II получение нитроаммофоски

Характеристика образцов упаренной ЭФК:

содержание $\mathrm{P}_{2} \mathrm{O}_{5}, \%$

содержание $\mathrm{F}, \%$

общая степень нейтрализации, \%

$\mathrm{pH}$ аммонизации

Состав продукта, \%:

усвояемая $\mathrm{P}_{2} \mathrm{O}_{5}$

водорастворимая $\mathrm{P}_{2} \mathrm{O}_{5}$

азот

$\mathrm{K}_{2} \mathrm{O}$

Сумма питательных веществ

Отношение $\mathrm{N}: \mathrm{P}_{2} \mathrm{O}_{5}$

\begin{tabular}{|c|c|c}
51,6 & 47,5 & - \\
0,6 & 0,6 & - \\
31 & 40 & - \\
7,0 & 6,5 & - \\
16,8 & 16,2 & - \\
14,7 & 15,0 & - \\
21,0 & 19,7 & - \\
17,0 & 16,6 & - \\
54,1 & 52,3 & - \\
$1: 0,77$ & $1: 0,81$ & -
\end{tabular}

из Рягавере расход $\mathrm{H}_{2} \mathrm{SO}_{4}$ был больше, производительность фильтрации ниже, а степень нейтрализации продукционной кислоты возрастала до $37-41 \%$. Повышение температуры экстракции от 75 до $90^{\circ} \mathrm{C}$ при переработке пробы 1 улучшало фильтруемость фосфогипса, если концентрация ЭФК не превышала $20 \%$. Полученные пробы ЭФК были переработаны в аммофос и нитроаммофоску.

Получение аммофоса (АФ). В качестве сырья использовали образцы неупаренной ЭФК, которые аммонизировали до $\mathrm{pH} 5$. В ходе аммони- 
Зависимость содержания усвояемой (сплошные кривые) и водорастворнмой (пунктирные кривые) $\mathrm{P}_{2} \mathrm{O}_{5}$ aммофоса от содержания примесей в фосфорите (кривые 1 и 2) и от степени нейтрализации ЭФК (кривые 3 , 4). Горизонтальными линиями обозначены минимальные содержания усвояемой (сплошные линии) и водорастворимой $\mathrm{P}_{2} \mathrm{O}_{5}$ (пунктирные линии) в аммофосе по ГОСТу 18918-79; линии 5 и 6 соответствуют высшему, линии 7 и $8-$ первому сорту.

зации при рН 2 происходило загустевание пульпы, а при сушке наблюдалось прилипание продукта к стенке сушилки.

Из фосфорита 1 был получен АФ высокого качества (табл. 4), содержащий около $51 \%$ усвояемой и $45 \%$ водорастворимой $\mathrm{P}_{2} \mathrm{O}_{5}$. Продукт из фосфорита 2 содержит меньше $\mathrm{P}_{2} \mathrm{O}_{5}$, но также отвечает требованиям высшего сорта по ГОСТу 18918-79. Аммофос из фосфорита 3 был нестандартным по содержанию усвояемой $\mathrm{P}_{2} \mathrm{O}_{5}$. Анализ экспериментальных данных показывает, что качество и сортность аммофоса определяются степенью нейтрализации используемой ЭФ̆ ном фосфорите. Стандартный АФ из фосфорита Рягавере получается при железисто-магнезиальном модуле не более 22 или же при степени нейтрализации ЭФК не более $38-39 \%$ (рисунок).

Получение нитроаммофоски (НАФК). Использовали смесь упаренной ЭФК $\left(47-52 \% \quad \mathrm{P}_{2} \mathrm{O}_{5}\right)$ с азотной кислотой. В ходе упаривания наблюдалось выпадение осадка и загустевание ӘФК, а образец упаренной кислоты из фосфорита 2 при остывании превратился в студнеобразную массу. Аналогичное явление отмечено ранее при переработке фосфоритов Азери $\left.{ }^{15}\right]$ и Каратау $\left[{ }^{16}\right]$ и объясняется выпадением фторида магния. При упаривании содержание фтора в ӘФК снижалось, а степень нейтрализации кислоты практически не изменялась.

Переработка загустевших магнийсодержащих проб ЭФК в нитроаммофоску возможна путем их подогревания и смешения с разбавленной азотной кислотой. Нормальные физико-химические свойства продуктов обеспечиваются проведением аммонизации пульпы до pH 6,5-7,0. Пульпа нитроаммофоски сушится лучше, чем аммофос. Продукты из проб фосфорита 1 и 2 по химическому составу отвечают требованиям ГОСТа 19691-80 к марке «А», но имеют некоторый избыток азота (отношение $\mathrm{N}: \mathrm{P}_{2} \mathrm{O}_{5}$ составляет $\left.1: 0,8\right)$. Суммарное содержание питательных веществ в пробах НАФК составляет $52-54 \%$, т. е. весьма высоко.

В результате проведенного исследования химической переработки фосфоритов Рягавере установлена зависимость качества продуктов от состава сырья и указаны условия для получения стандартных удобрений. Наиболее рационален из всех изученных - вариант получения аммофоса на основе фосфоритного концентрата с меньшим количеством магния. Необходимо продолжение работ по более эффективному обогащению руды и химической переработке фосфоритных концентратов Раквереского месторождения, в частности, по схеме азотнокислотного разложения. 
1. Р аудсеп Р., Эскель. Ю. Особенности геологического строения фосфоритоносной толщи южнее месторождения Тоолсе. - Изв. АН ЭССР. Геол., 1980, т. 29 , № 2 , с. $84-86$.

2. Петросянц Э., 3 агураев В., Кивит А., Мустйыги Э. Состояние и перспективы промышленного освоения Раквереской фосфоритоносной площади. - Изв. АН ЭССР. Геол., 1981, т. 30, № 2, с. 79-82.

3. Цуцульковский В., Юрков Л., Кореньков а В. О флотационном обогащении ожелезненных фосфоритов Раквереского района ЭССР. - Изв. АН ЭССР. Хим., 1981, т. 30 , № 2, с. $106-110$.

4. Методы анализа фосфатного сырья, фосфорных и комплексных удобреннй, кормовых фосфатов. М., 1975.

5. Ок н н н а В.А. Методы анализа фосфатных руд. М., 1961.

6. Пылдме М. Э., Пылдме Ю. Х., Борисова Г. С. Определение фосфата усовершенствованным методом дифференциальной фотоколориметрии. - $\mathrm{T}$. Таллин. политехн. ин-та, 1976, № 397, с. 59-64.

7. Ando, J., Matsuno, S. The constitution, reactivity and thermal changes of phosphate ores. - Bull. Chem. Soc. Japan, 1966, v. 39, N 9, p. 1915-1922.

8. Вейдерм а M., Вескимяэ Х. Сравнительная физико-химическая и агрохимическая характеристика фосфоритных концентратов СССР. (Тр. научнотехн. конф. «Оболовые фосфориты как сырье для химической промышленности»). Таллин, 1968, с. $19-37$.

9. А а сам яэ Э. Э., В ейде р м а М. А. Получение экстракционной фосфорной кислоты и двойного суперфосфата из фосфоритных концентратов месторождения Тоолсе. - Хим. промышленность, 1978, № 3, с. 193-196.

10. А а самяэ Э., Вейде м а М., Р ебане А. Исследование переработки фосфоритов месторождения Азери в двойной суперфосфат. - Изв. АН ЭССР. Хим., 1979 , т. 28 , № 3, с. $198-203$.

11. А а самяэ Э. Э., В ейде рм а $M$. А., В ескимяэ Х. И. Получение экстракционной $\mathrm{H}_{3} \mathrm{PO}_{4}$ и аммофоса из термически обработанных фосфоритов бассейна Каратау. - Хим. промышленность, 1974, № 10, с. $756-759$.

12. Вейдерма M. А., А асамяэ Э. Э., Лутси ус Л. Р. Получение двойного суперфосфата из эстонских фосфоритов камерным способом. - Хим. промышленность, 1971 , № 10, с. $750-753$.

13. Ве йде р м а M. А., А а с а м я э Э. Э. Исследование поточного способа получения двойного суперфосфата с применением различных видов сырья. - Хим. промышленность, 1973, № 10, с. 756-759.

14. А а самяэЭ. Э., В ейдер м М. А., Р еб ан е А. И. Получение аммофоса и нитроаммофоски из фосфоритов месторождения Тоолсе. - Хим. промышленность, 1979 , № 12 , с. $722-724$.

15. А а с а м яэ Э., В ейде м м М., Р еб ан е А. Исследование получения фосфорной кислоты и сложных удобрений из фосфоритов месторождения Азери. - Изв. АН ЭССР. Хим., 1979, т. 28, № 3, с. 204-209.

16. Позин М. Е., В аршав ский В. Л., Одинцова Г. С., В ашкевич Н. Г. $\mathrm{K}$ вопросу о механнзме загустевания магнийсодержащей фосфорной кислоты. - В кн.: Технология минеральных удобрений. Л., 1977, с. 3-10.

таллинский политехнический институт

Поступила в редакцню 9/X 1981

\section{E. AASAMAE, M. VEIDERMA}

\section{RÄGAVERE FOSFORIIDI KOOSTIS JA HAPPELINE TÖOOTLEMINE}

Artikkel käsitleb Rägavere (Rakvere raj.) fosforiidi flotatsioonikontsentraatide väävelhappega töötlemise laboratoorset uurimist. On esitatud andmeid topeltsuperfosfaadi, ekstraktsioonfosforhappe ja liitväetiste (ammofoss ja nitroammofoska) kvaliteedi sõltuvuse kohta tooraines olevatest lisanditest $\left(\mathrm{MgO}, \mathrm{Fe}_{2} \mathrm{O}_{3}\right)$ ja näidatud standardsete väetiste saamise võimalusi.

\section{E. AASAMAEE, M. VEIDERMA}

\section{INVESTIGATION OF COMPOSITION AND ACID TREATMENT OF RÄGAVERE PHOSPHORITE}

The obtaining of double superphosphate, phosphoric acid and complex fertilizers (monoammonium phosphate and nitroammophoska) from flotation concentrates of Rägavere phosphorite (Estonian SSR) has been studied. Data are given concerning the influence of magnesium and iron content of the phosphorite on the quality of the fertilizers mentioned above. Conditions for receiving standard fertilizers are pointed out. 